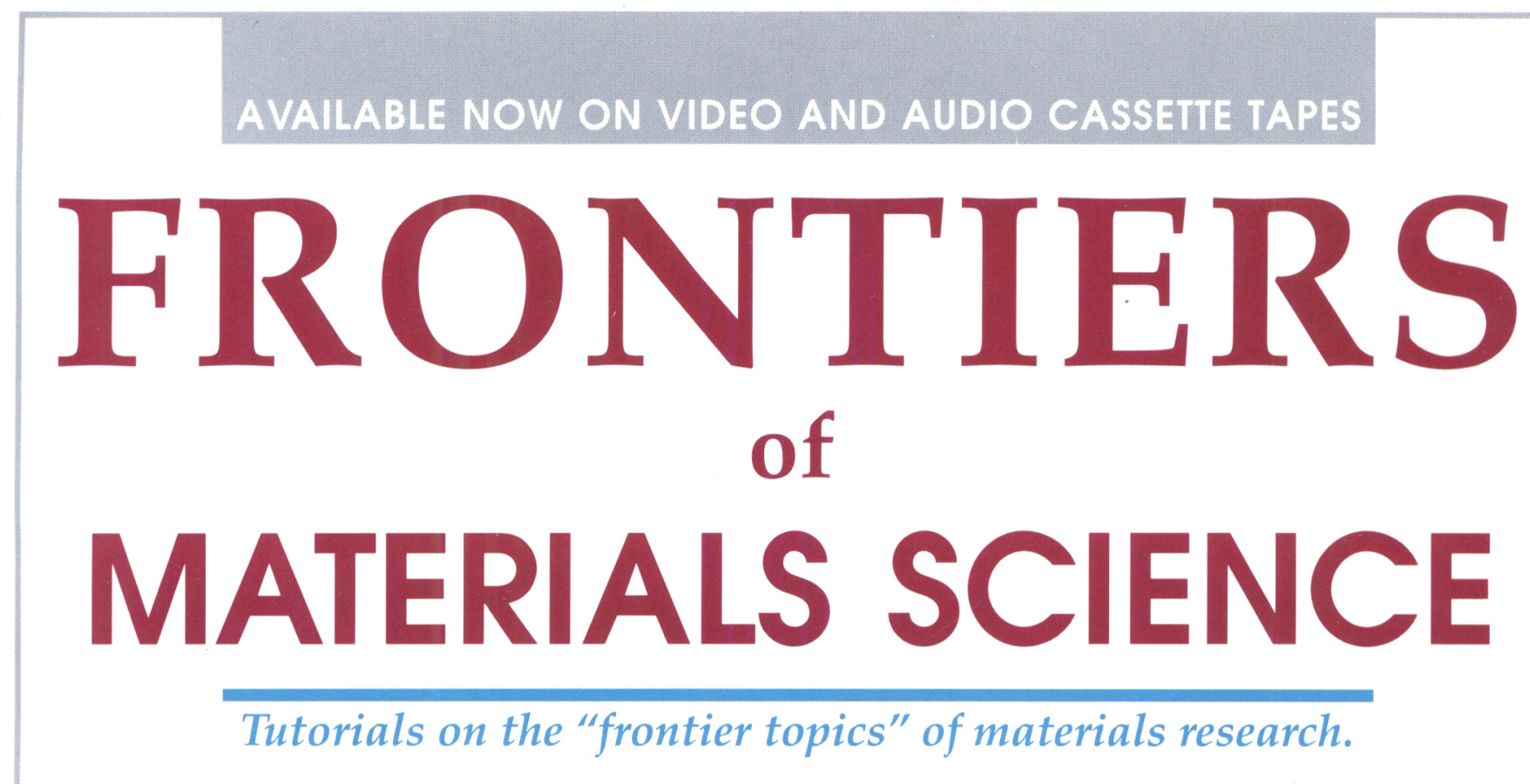

\title{
TITLE AND SPEAKER
}

Defect Engineering in Semiconductors (H.C. Gatos, MII)

Recent Advances in Polymers

(H. Mark, Polytechnic Institute of New York)

Superconductor Design and Application (E.W. Collings, Battelle Columbus Laboratories)

\section{Tribology Update}

(K.C. Ludema, University of Michigan)

Mechanics of Electronic Packaging Materials (H. Hieber, Philips GmbH)

A Case History of Materials Development: Optical Fibers

(J.B. MacChesney, AT\&T Bell Laboratories)
State of the Art Non-Destructive Evaluation

(R. Greene, Jr., Johns Hopkins University)

New Materials Technology for Highways

(R. Decker, University Science Partners)

Fractals and Disorderly Growth (P. Meakin, E.I. duPont de Nemours \& Company)

Ultrathin Film Growth from Langmuir Blodgett to Self-Assembly

(A. Ulman, Eastman Kodak Company)

Failure Analysis in Materials Research (M. Louthan, Jr., Savannah River Laboratory)

Properties of Hydrogenated Amorphous Silicon (R. A. Street, Xerox Palo Alto Research Center)

\begin{tabular}{|c|c|c|c|}
\hline $\begin{array}{c}\text { Prices } \\
\text { (per tape)* }\end{array}$ & $\begin{array}{c}\text { VHS } \\
1 \text { tape } / 3+\text { tapes }\end{array}$ & $\begin{array}{c}\text { U-Matic } \\
1 \text { tape } / 3+\text { tapes }\end{array}$ & $\begin{array}{c}\text { Audio Cassette } \\
1 \text { tape } / 3+\text { tapes }\end{array}$ \\
\hline MRS Members & $\$ 30$ ea. $/ \$ 25 e a$. & $\$ 45 e a . / \$ 40 e a$. & $\$ 12 e a . / \$ 8 e a$. \\
U.S. List & $\$ 36 e a . / \$ 32 e a$. & $\$ 55 e a . / \$ 50$ ea. & $\$ 16 e a . / \$ 12 e a$. \\
Foreign & $\$ 45 e a . / \$ 41$ ea. & \$65ea. $/ \$ 60 e a$. & $\$ 20$ ea. $/ \$ 16 e a$. \\
\hline
\end{tabular}

Also available on VHS and U-Matic: "High Temperature Superconductors," tapes of two recent MRS Symposia; and Linus Pauling's Plenary Address at the 1989 MRS Spring Meeting.

For further information, or to order, contact the Publications Department at: 


\section{SEE IT LIKE IT IS}

\section{TAKE THE "WAIT AND SEE" OUT OF YOUR X-RAY WORK.}

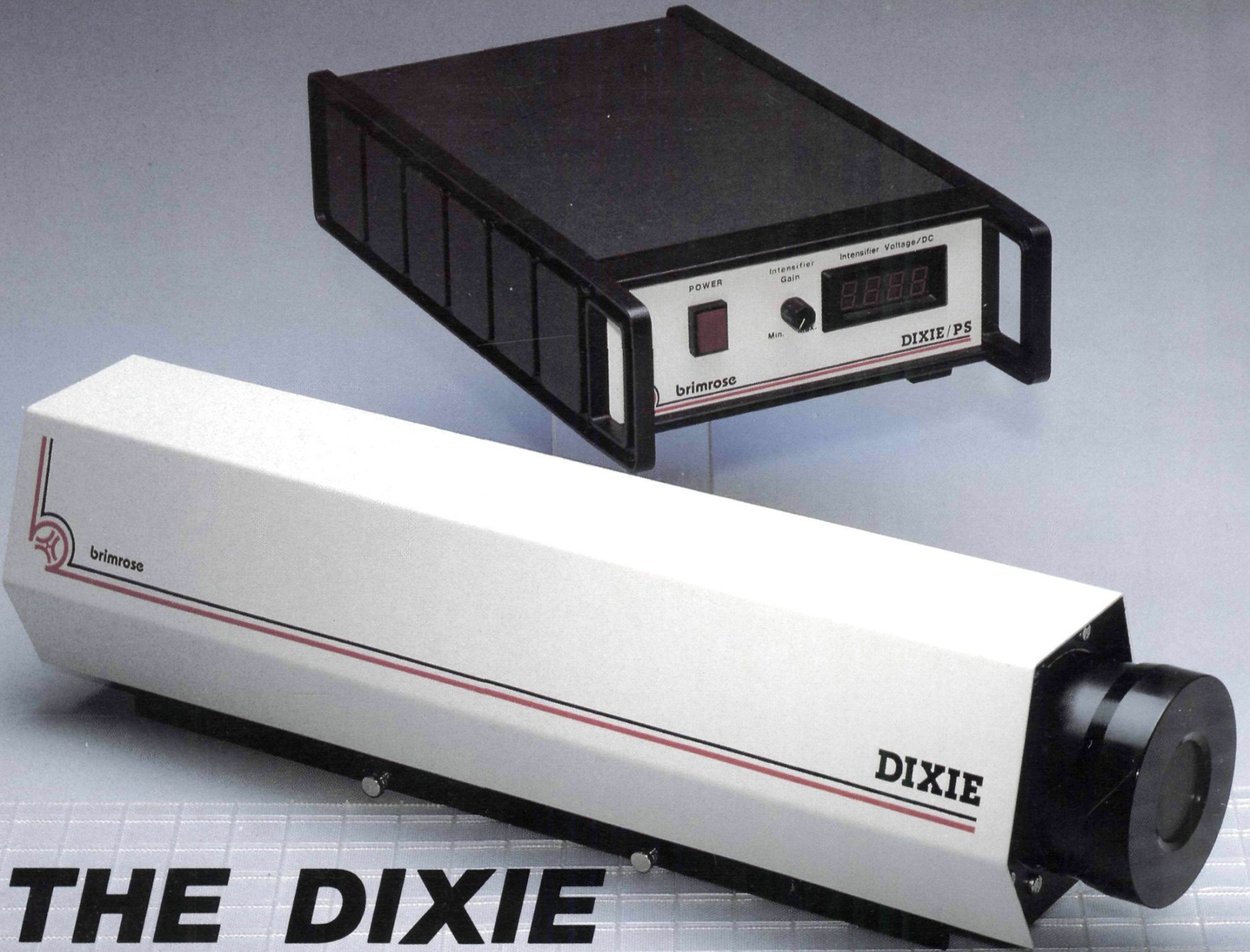

\section{DIGITAL INTENSITY X-RAY IMAGE NHANGER}

system brings real time x-ray imaging to your lab. With a full $40 \mathrm{~mm}$ diameter input window and up to 200,000 gain. You can see immediately what film gives you later.

\section{CONTACT US FOR MORE INFORMATION:}

For inquiries on career opportunities with a leader in the electronic defense industry, contact us. We are an equal opportunity employer.

- acousto-optic ox-ray oinfrared. systems

brimrose corporation of america 7720 belair rond 